\title{
Ice particles in the upper anvil regions of midlatitude continental thunderstorms: the case for frozen-drop aggregates
}

\author{
J. L. Stith ${ }^{1}$, L. M. Avallone, ${ }^{2,}$, A. Bansemer ${ }^{1}$, B. Basarab ${ }^{3}$, S. W. Dorsi ${ }^{4}$, B. Fuchs ${ }^{3}$, R. P. Lawson ${ }^{5}$, D. C. Rogers ${ }^{1}$, \\ S. Rutledge ${ }^{3}$, and D. W. Toohey ${ }^{6}$ \\ ${ }^{1}$ National Center for Atmospheric Research, Boulder, Colorado, USA \\ ${ }^{2}$ Laboratory for Atmospheric and Space Physics, University of Colorado Boulder, Colorado, USA \\ ${ }^{3}$ Colorado State University, Fort Collins, Colorado, USA \\ ${ }^{4}$ CIRES, University of Colorado and NOAA-ESRL, Boulder, Colorado, USA \\ ${ }^{5}$ SPEC Incorporated, Boulder, Colorado, USA \\ ${ }^{6}$ Department of Atmospheric and Oceanic Sciences, University of Colorado Boulder, Colorado, USA \\ *now at: National Science Foundation, Arlington, Virginia, USA
}

Correspondence to: J. L. Stith (stith@ucar.edu)

Received: 25 September 2013 - Published in Atmos. Chem. Phys. Discuss.: 17 October 2013

Revised: 9 January 2014 - Accepted: 14 January 2014 - Published: 20 February 2014

\begin{abstract}
This study examines the occurrence and morphology of frozen-drop aggregates in thunderstorm anvils from the United States Midwest and describes the environmental conditions where they are found. In situ airborne data collected in anvils using several particle imaging and sizing probes and bulk total water instrumentation during the 2012 Deep Convective Clouds and Chemistry experiment are examined for the presence of frozen-drop aggregates. Chains of frozen drops have been only rarely reported before and are hypothesized to aggregate due to electrical forces in the clouds. They were identified in nine of the anvil cases examined to date, suggesting that they are common features in these Midwestern anvils. High concentrations of individual frozen droplets occurred on the tops and edges of one particular set of anvils, while regions closer to the center and bottom of these anvils exhibited fewer frozen drops and more frozen-drop aggregates. Bulk ice water content measurements across these anvils could only be explained by contributions from both small particles (frozen droplets) and large particles (large aggregates of frozen droplets). Dual Doppler radar analysis confirmed the presence of deep and strong $\left(>15 \mathrm{~m} \mathrm{~s}^{-1}\right)$ updrafts in the parent cloud of one of the anvils. These features contrast with previous anvil measurements in tropical/maritime anvils that evidently do not exhibit the same frequency of frozen-drop aggregates.
\end{abstract}

\section{Introduction}

Thunderstorms are an important source of ice particles to the upper troposphere and lower stratosphere, yet we are still learning about how these ice particles are formed and how their properties change in different locations and in different types of storms. The origins and lifetimes of the particles, their radiative properties, and their chemical composition are likely to be quite different for different types of ice particles, yet we do not have a complete inventory of particle types found in the upper regions of thunderstorm clouds. Recently, Gayet et al. (2012) described observations of small chainlike aggregate ice crystals, formed from frozen drops, in an overshooting top from a deep convective cloud in western Europe, using the Stratton Park Engineering Company Inc. (SPEC) Cloud Particle Imager (CPI) and other instruments. Their CPI images of these frozen-drop aggregates are similar to those first observed by Lawson et al. (2003) in Colorado thunderstorm anvils (discussed below). The use of the CPI in these studies is significant because, unlike traditional optical array probe (OAP) imaging instruments, this instrument has enough resolution $(2.3 \mu \mathrm{m})$ that together with its 256 grey levels provide the necessary definition to resolve individual frozen droplets. Thus, the morphology of the aggregates can be examined. Chain-like aggregates in thunderstorms have been reported in several locations and are 
thought to aggregate due to electrical forces (Connolly et al., 2005; Lawson et al., 2003; Stith et al., 2002, 2004). Most of the chain aggregates reported to date in tropical and lowlatitude clouds have been composed of aggregates of faceted ice crystals rather than frozen droplets. Relatively few highaltitude CPI measurements are available in strong continental thunderstorms, where Gayet et al. (2012) and Lawson et al. (2003) observed the frozen-drop chain aggregates. Thus, it is unclear how widely these frozen-drop chain aggregates are found, and the environmental conditions that are responsible for their formation need to be better understood.

Lawson et al. (2003) analyzed 8600 CPI images from three different passes made through continental Colorado anvils at temperatures of $-47{ }^{\circ} \mathrm{C}$. They reported that $2-3 \%$ of the images were chain aggregates, 4-6\% were doublets, and 25-32\% were other aggregates (the remaining particles were other particle types, such as spheroids). They did not segregate between frozen-drop chain aggregates and other chain aggregates, but the imagery they reported showed a preponderance of frozen-drop aggregates in the Colorado anvils. They also did a similar analysis of $16600 \mathrm{CPI}$ images taken at temperatures between -5 and $-60{ }^{\circ} \mathrm{C}$ in three tropical maritime anvils that formed near Kwajalein. In these cases they found $0 \%$ chains, $0.1-2.3 \%$ doublets, and 0.4 to $1.4 \%$ other aggregates (the remaining particles were other particle types, such as blocky irregulars, and spheroids). Their observations of some doublets for the Kwajalein cases, albeit in significantly lower proportions than in the Colorado anvils, suggest that some aggregation of frozen droplets is occurring in the Kwajalein clouds, but that the process is much less important than in the Colorado clouds. In contrast to the Lawson et al. (2003) findings for chain aggregates in the Kwajalein clouds, Stith et al. (2004) reported similar types of chain aggregates in CPI images (chains of faceted crystals, but not chains of frozen droplets) from Kwajalein clouds to ones they found in Brazilian tropical convective systems. Thus there is a need for more complete inventories of chainaggregate particles and their precursors in different types of storm conditions.

In this paper, we report on observations of frozen-drop aggregates and frozen-drop chain aggregates made in the upper regions of several midlatitude thunderstorm anvils over the continental United States (US) during the Deep Convective Clouds and Chemistry (DC3; Barth et al., 2012) experiment. Our results suggest that these types of aggregates are common in the upper levels of these storms and, together with individual frozen droplets, can dominate the particle types in the upper anvil. These frozen-drop aggregates include particles that are chain-like as well as frozen doublets, triplets, and quasi-spherical aggregates, so we refer to this entire class of particles as frozen-drop aggregates (FDAs). After describing the experimental techniques, we analyze the ice particle morphology and microphysical characteristics of two FDAcontaining upper anvils in eastern Colorado, and then present a survey identifying other storm anvils where similar FDAs were found.

\section{Instrumentation and experimental techniques}

Thunderstorm sampling was conducted during DC3 in late spring and early summer of 2012. The purpose of DC3 was to investigate the impact of deep, midlatitude continental convective clouds on upper tropospheric chemistry and composition. It utilized multiple research aircraft, including the National Science Foundation (NSF)/National Center for Atmospheric Research (NCAR)'s Gulfstream five (G-V) aircraft, the National Aeronautics and Space Administration (NASA)'s DC-8, and the Deutsches Zentrum für Luft- und Raumfahrt (DLR) Falcon. Ground-based observations included Doppler radars and lighting mapping arrays. These tools were used to study the dynamics of convective storms and their chemical properties, such as $\mathrm{NO}_{\mathrm{x}}$ production by lightning and convective transport and transformation of various chemical species. The observations were conducted in three locations, northeastern Colorado, west Texas to central Oklahoma, and northern Alabama. This allowed sampling to be done in different types of storms. Because a major focus of the $\mathrm{DC} 3$ project was on $\mathrm{NO}_{\mathrm{x}}$ production by lightning, nearly all of the storms chosen for sampling exhibited significant or intense lightning activity, so the charge separation process was certainly present in these clouds. As a part of the next phase of our study we intend to examine the DC3 lightning mapping array data to determine if it can help explain the occurrence of the chain-aggregate FDAs in these storms. For this paper, airborne data from the NSF/NCAR G-V are utilized, as it was the only aircraft to carry the CPI during DC3, but future studies are planned using the larger data sets provided in DC3 (including the 2D-S portion of the $3 \mathrm{~V}-\mathrm{CPI}$ probe).

The G-V's capabilities and standard instrumentation are described in the G-V investigator's handbook, which is available at http://www.eol.ucar.edu/content/ nsfncar-gv-investigator-handbook. Standard measurements included location, temperature, pressure, three-component wind (measured with an inertial navigation-gust probe system), along with chilled mirror and optical absorption humidity instruments. Relative humidity data presented below are from the Vertical Cavity Surface Emitting Laser (VCSEL) hygrometer, which is described in Zondlo et al. (2010).

Other instrumentation used in this study includes a specially modified Particle Measuring Systems (PMS) optical array probe (OAP-2DC), which uses high-speed electronics and a 64-element $25 \mu \mathrm{m}$-resolution diode array in order to shadow particles at the sampling speeds of the G-V. To reduce uncertainties in the depth of field, we only report on particles that shadow three or more diodes (i.e., a midpoint of $75 \mu \mathrm{m}$ and above). Processing of OAP data fits the smallest 
possible circle around a particle image and uses the diameter of that circle as the diameter of the particle; this allows the "roundness" of the particles to be ascertained, and the circle can be fit to particles that only image part of the $1.6 \mathrm{~mm}$ array. This allows particles up to $3.2 \mathrm{~mm}$ to be sized.

Shattering of particles is a major problem affecting airborne ice particle measurements, especially when large particles are present (e.g., Korolev et al., 2011, 2013; Lawson, 2011). This is thought to occur due to mechanical impact of particles with probe surfaces and aerodynamic stresses caused by the flow around the probe housing, which may cause particle breakup (Korolev et al., 2013, and references therein). Two methods are used to minimize the effects due to shattering in the OAP-2DC data. First, anti-shattering tips were utilized in DC3. These wedged-shaped tips were similar to but simpler than the "k-tips" described by Korolev et al. (2013). In-cloud comparisons of the DC3 tips with standard 2DC tips indicate that they are quite effective at reducing shattering. The effects of shattering are also corrected using software corrections, following the procedures outlined in Field et al. (2006). The combination of the two techniques offers the best chance of minimizing the effects due to shattering artifacts (Korolev et al., 2013). As suggested in Korolev et al. (2013), it is probably not possible to completely know the residual effects of shattering even when all these methods are employed. While there may still be some residual shattering impacts on the total OAP-2DC concentration, impacts on higher moments of the size distribution, such as total particle volume/mass concentration, are likely to be minor (Korolev et al., 2013).

A Cloud Droplet Probe (CDP, manufactured by Droplet Measurement Technologies, DMT) is used in this study. The CDP is an unshrouded forward-scattering instrument that is optimized and calibrated for sampling cloud droplets in the size range of $2-50 \mu \mathrm{m}$ diameter. A similar but shrouded instrument, the PMS Forward Scattering Spectrometer Probe (FSSP), has been used for measuring ice concentrations in cirrus (e.g., Krämer et al., 2009; Heymsfield et al., 2009), although the response to large nonspherical ice is uncertain and the potential shattering effects from larger ice particles hitting the FSSP shroud are important (e.g., Gardiner and Hallett, 1985). Because the CDP does not have a shroud, the shattering effects should be much smaller than for the FSSP. Testing we have done (unpublished results) of the CDP conducted in large (mm-sized) aggregates in completely glaciated clouds (no supercooled liquid water detected by a Rosemount icing probe), but at warmer temperatures than in this study, indicated artifact concentrations due to shattering were of order $\sim 0.1 \mathrm{~cm}^{-3}$. An instrument such as the CDP, since it is optimized and calibrated for spherical particles, should work best at sampling small ice if the ice is approximately spherical and in the size range of the instrument. However, the relatively small sample volume of this instrument typically requires long sampling times in most ice clouds. Data presented here are unusual in this regard be- cause, as shown below, high concentrations of frozen spherical droplets are present in these anvil clouds, which allow the CDP to be used more effectively than in other ice clouds.

A SPEC 3V-CPI combination Cloud Particle Probe was used in this study. This is a relatively new instrument that was developed to overcome limitations of the CPI, by replacing the two photodiode triggers of the CPI with the two 128-photodiode arrays of the SPEC 2D-S OAP instrument. More information is provided at http://www.specinc. com/3v-cpi-combo. The SPEC 2D-S OAP utilizes two 128 photodiode arrays with $10 \mu \mathrm{m}$ resolution in a horizontal and vertical arrangement that gives two views of the sampling domain, while the CPI portion of the instrument retains the resolution of earlier versions of the CPI, $2.3 \mu \mathrm{m}$.

Total condensed water within clouds was determined using the University of Colorado Closed-path Laser Hygrometer, Version 2 (CLH-2) (Dorsi et al., 2013). CLH-2 uses tunable diode laser absorption spectroscopy to measure the sum of ambient water vapor and that produced by sublimation of ice and evaporation of liquid, enhanced by nearly several orders of magnitude with a subisokinetic inlet. Condensed-phase water in clouds is determined by subtracting the signal from background water vapor measurements and correcting for the particle enhancement based on detailed computational fluid dynamical calculations. CLH-2 derives from the University of Colorado Closed-path Laser Hygrometer (CLH), which has flown hundreds of hours on research aircraft, including the NSF/NCAR G-V and C-130 and the NASA DC-8 and WB-57F. The measurement technique, which is common to CLH and CLH-2, has been described in Davis et al. (2007a, b). CLH-2 was first deployed on an aircraft during DC3 and is currently undergoing in-flight intercomparisons with other condensed water measurements to assess the uncertainties in the enhancement factor, the largest source of uncertainty in the measurement. The measured ice water content (IWC) is only weakly dependent on the particle size distributions at the high-altitude and high-airspeed conditions where sampling typically occurred during DC3. Unpublished computational fluid dynamics calculations done specifically for the CLH-2 at the G-V sampling conditions suggest that the particle aspiration efficiency was within 4 to $6 \%$ of the inertial enhancement ratio (ratio of air velocities) for spherical diameters greater than $25 \mu \mathrm{m}$ and condensed-phase density of around $1 \mathrm{~g} \mathrm{~cm}^{-3}$. A similar result for the CLH-1 instrument is shown in Fig. 4 of Davis et al. (2007a). For the DC3 sampling conditions, we estimate particle size distribution effects to be less than $2 \%$ of the measured IWC, although, as discussed later, the aspiration efficiency could be overestimated for particles that are significantly nonspherical and fragile, such as some of the long-chain aggregates observed in this study.

Most flight samples reported here were from flight traverses of the anvil clouds approximately perpendicular to their long axis at various altitudes and distances from the main convective cell of the storm. 

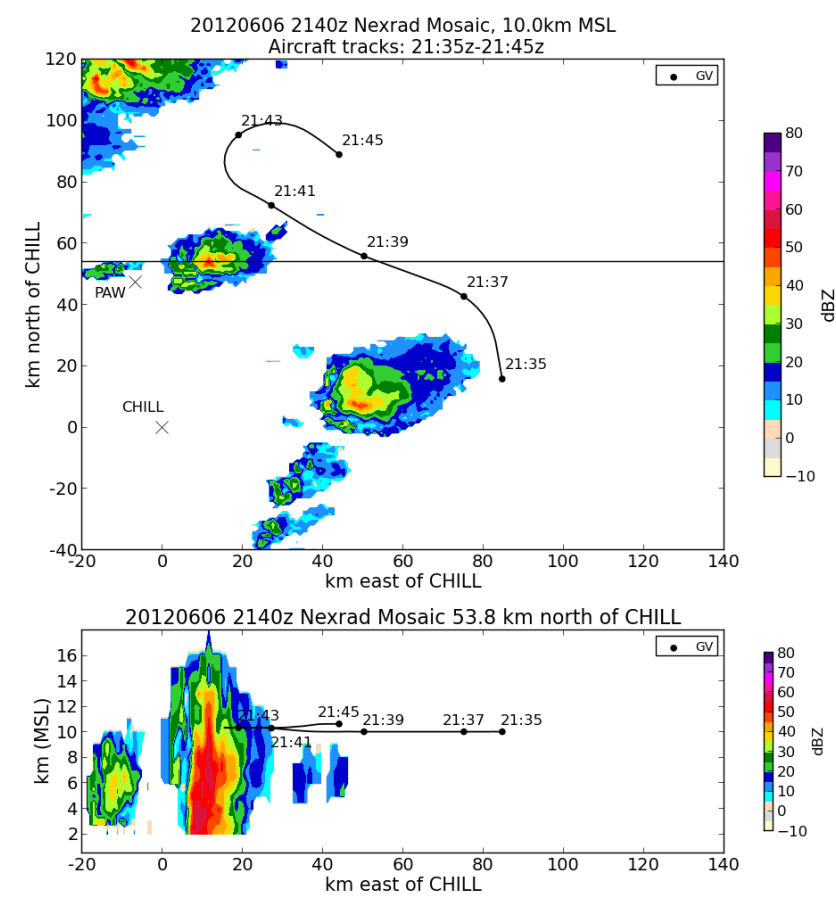

Fig. 1. Nexrad composite radar returns at 21:40 from the anvilproducing storms that were sampled later in the flight. At this point in the flight the G-V flew next to the developing anvils, in primarily clear air. The lower panel depicts a radar cross section through the northern storm at the location indicated by the line near $55 \mathrm{~km}$ north of CHILL in the top figure. The projection of the flight track on the cross section is also provided in the lower figure (although the flight track did not encounter significant cloud as evidenced by the top figure). The location of the Pawnee and CHILL radar sites is included for reference.

\section{Observations and measurements in the upper anvils of two storms}

\subsection{Overview of storms}

Measurements were made in the upper regions of two anvils from storms that occurred on 6 June 2012 in eastern Colorado, near the CHILL radar site. Both storms (a north storm and a south storm) were similar in size and intensity and separated by about $70 \mathrm{~km}$, based on the storm structure depicted by the NEXRAD radar (Fig. 1) at 21:40 (all times are in UTC), roughly $31 \mathrm{~min}$ before the sampling described below. Radar tops were in excess of $15 \mathrm{~km}$ altitude (Fig. 1; all altitudes are reported above mean sea level, MSL). A photograph of the anvil from the southern storm, just before the sampling started, is provided in Fig. 2. The flight track of the G-V through the anvils is provided in Fig. 3, which also shows the NEXRAD radar and Geostationary Operational Environmental Satellite (GOES) visible imagery at 22:15. A comparison of Figs. 1 and 3 shows the development of the anvil during this period. Altitude, temperature, concentrations of ice from the CDP and 2DC instruments, and the

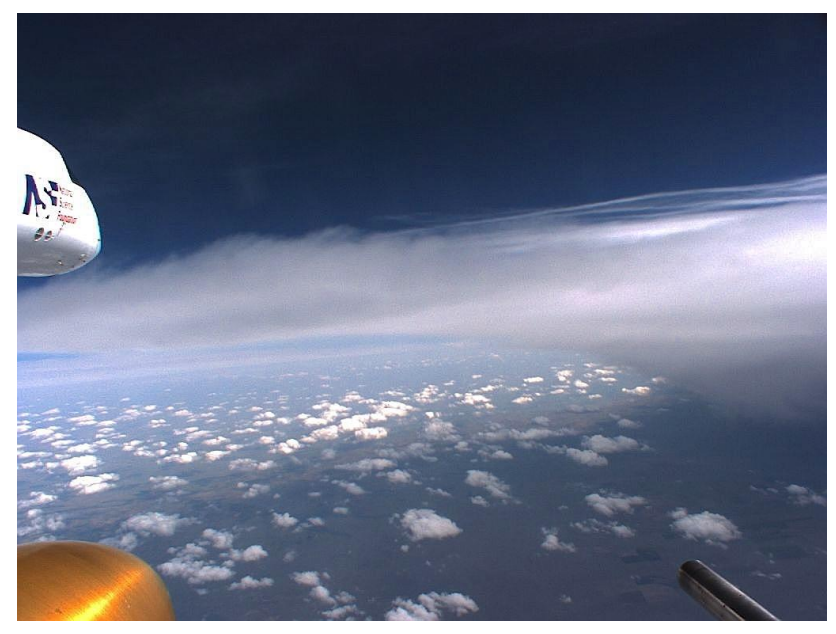

Fig. 2. Photograph of the anvil from the south storm at 22:10:56, just before sampling began.

relative humidity with respect to ice (measured by the VCSEL instrument) are provided in Fig. 4.

A climb through the far-downwind (i.e., eastern) portion of the anvil was performed during pass 1 , beginning at the northern edge and ending near the southern edge (Fig. 3) on a southerly heading. At this location, the anvil was approximately $0.6 \mathrm{~km}$ thick and covered an altitude of 11.7 to $12.3 \mathrm{~km}\left(-56\right.$ to $-60^{\circ} \mathrm{C}$, Fig. 4). Following the first pass through the anvil a repeat pass was made in a northwesterly direction (Fig. 3) at $12 \mathrm{~km}$ altitude and $-54^{\circ} \mathrm{C}$, which took the sampling somewhat closer to the main cell (Figs. 3 and 4). Finally, the anvil from the northern storm was sampled at the same altitude following pass 2 though the southern anvil (Figs. 3 and 4). Following the sampling near the upper anvil, the anvils were sampled at slightly lower altitudes (10.8 to $11.1 \mathrm{~km},-47$ to $-50^{\circ} \mathrm{C}$ ), which were nearer the visual base of the anvil and included fallout of particles beneath the core of the anvil (discussed below).

\subsection{Morphology of particle types revealed by CPI imagery and OAP instruments}

A review of CPI imagery, for images that were in focus, revealed distinct signatures of frozen droplets, chains of various lengths composed of frozen droplets, and more rounded FDAs. Examples of CPI imagery from the upper anvil are given in Fig. 5 (primarily frozen drops, with occasional FDAs), Fig. 6 (a mix of frozen drops and FDAs) and Fig. 7 (frozen drops, chains and larger FDAs). As is clear from the examples shown in Figs. 5-7, most CPI images in these anvil regions exhibited frozen droplets, doublets, triplets, and particles containing larger numbers of frozen droplets. For the in-focus FDA images, the frozen droplets are approximately $20-25 \mu \mathrm{m}$ in diameter, which is consistent with our identification as frozen single droplets. Only a few distinct 

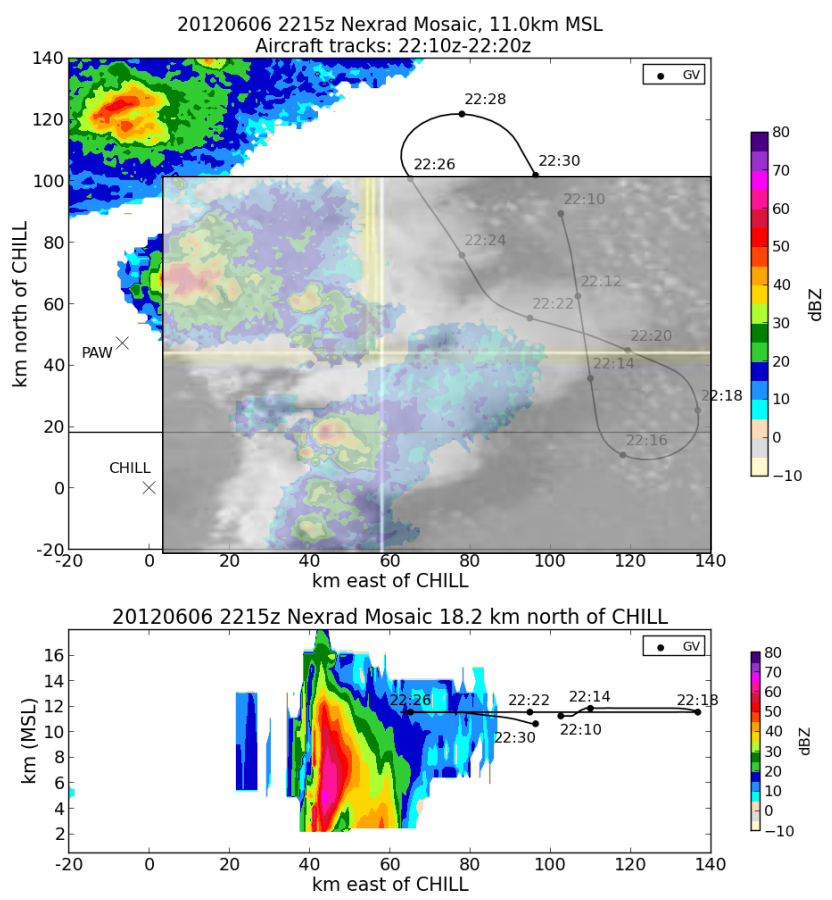

Fig. 3. Track of the G-V during upper anvil sampling of the anvils from the north and south storm on 6 June 2013 together with the 22:15 NEXRAD composite radar. The lower panel depicts a radar cross section through the southern storm at the location of the line near $20 \mathrm{~km}$ north of CHILL in the top figure. A portion of the 22:15:12 GOES-13 visible satellite image is overlaid on the radar image (the yellow lines on the image depict the ColoradoNebraska-Wyoming state boundaries). The projection of the flight track on the radar cross section is provided in the lower figure (as depicted in the upper figure, the flight track encountered cloud but not significant radar returns). The location of the Pawnee and CHILL radar sites is included for reference.

faceted ice crystal images were observed in thousands of these images, suggesting the dominant particle types were frozen droplets and FDAs, rather than crystals grown from the vapor. The imagery suggests that the anvil at these altitudes contained primarily frozen droplets that had aggregated to varying degrees across the anvil.

We expect that the numbers of single-drop images (as well as doublets and higher-order aggregates) will vary greatly with the degree of aggregation in the cloud. These observations should also be affected to a significant degree by shattering of particles during sampling, as discussed below. This would likely decrease the numbers of larger FDAs and produce smaller FDA particles or even single droplets. To provide an example of the relative number of different types of particles, we examined 3125 images from the period 22:11 to 22:15 that were deemed (by eye) sufficiently focused to discern the morphology of the particles. This period, during the first pass through the southern storm anvil (Fig. 3), had fewer very large aggregate particles and produced images typically
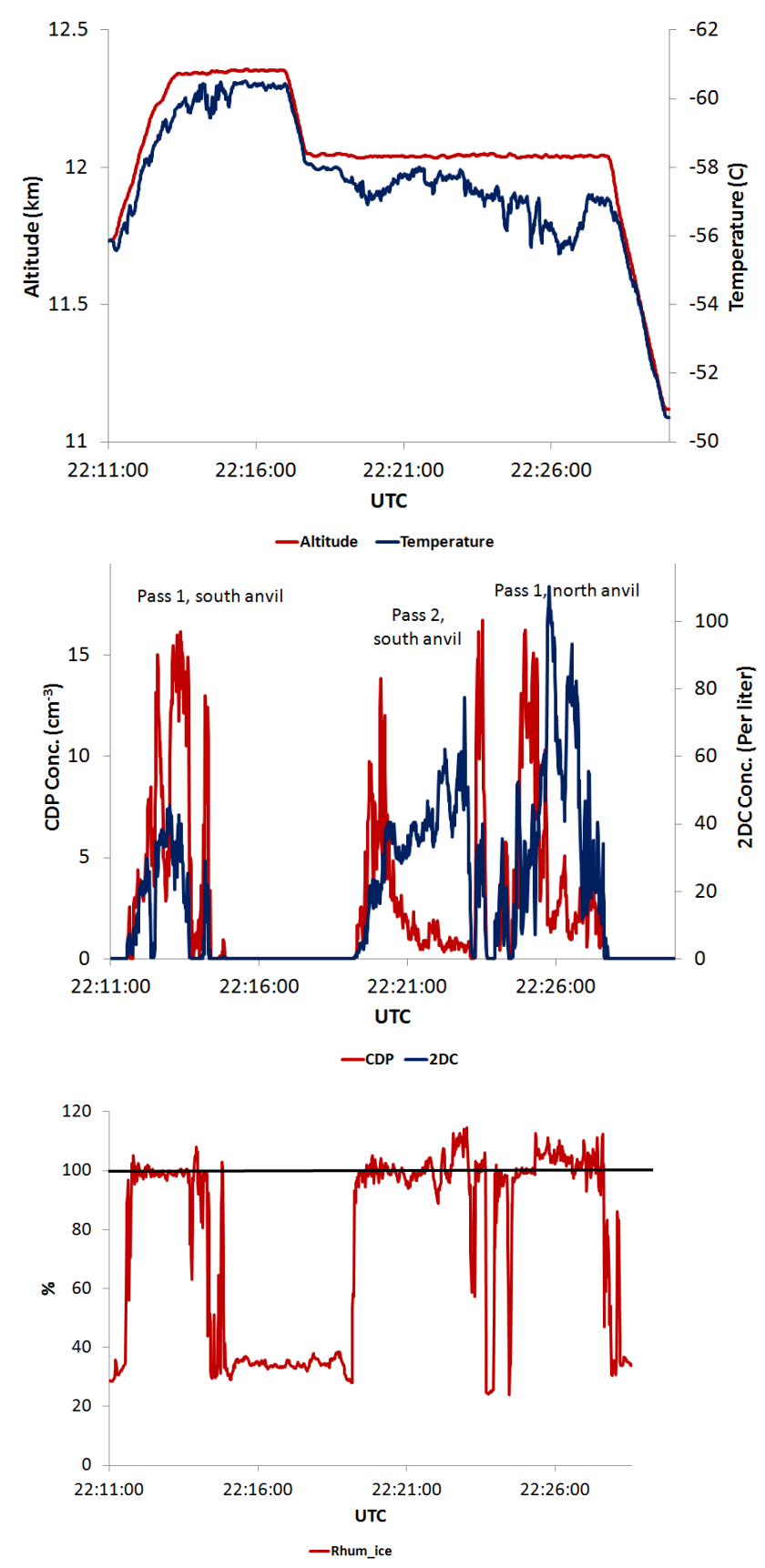

Fig. 4. Altitude (red) and temperature (blue) for the anvil passes (top), corresponding concentrations from the CDP (red) and 2DC (blue) instruments (middle) and relative humidity with respect to ice (bottom).

similar to those shown in Fig. 5. Approximately $81 \%$ of the 3125 images were classified as single frozen drops, $9 \%$ were classified as doublets, $2 \%$ were triplets, and $8 \%$ were larger FDAs. Although this region had somewhat fewer large FDAs than later sampling, these numbers are undoubtedly affected by shattering to some degree. However, these results suggest an abundance of images of each particle type as features 


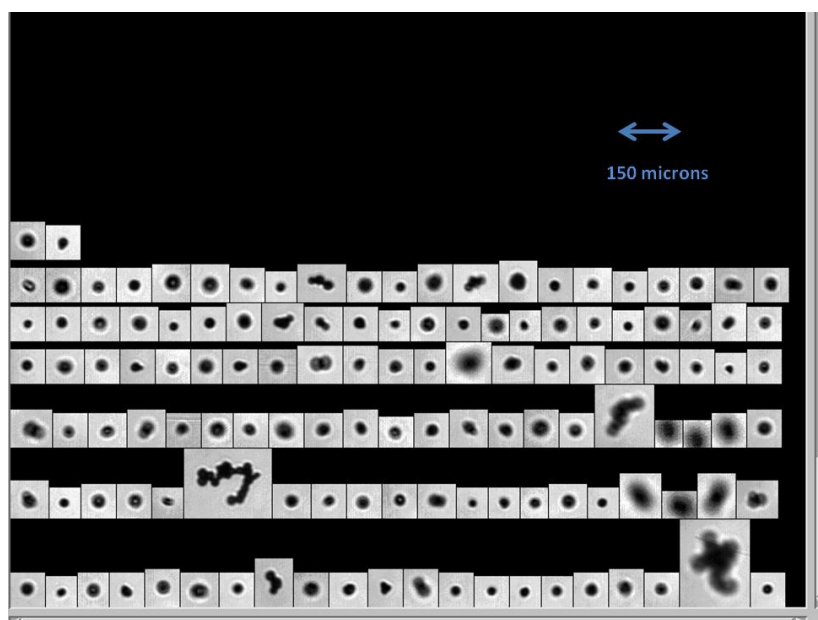

Fig. 5. CPI images of ice particles sampled between 22:13:04 and 22:13:06.

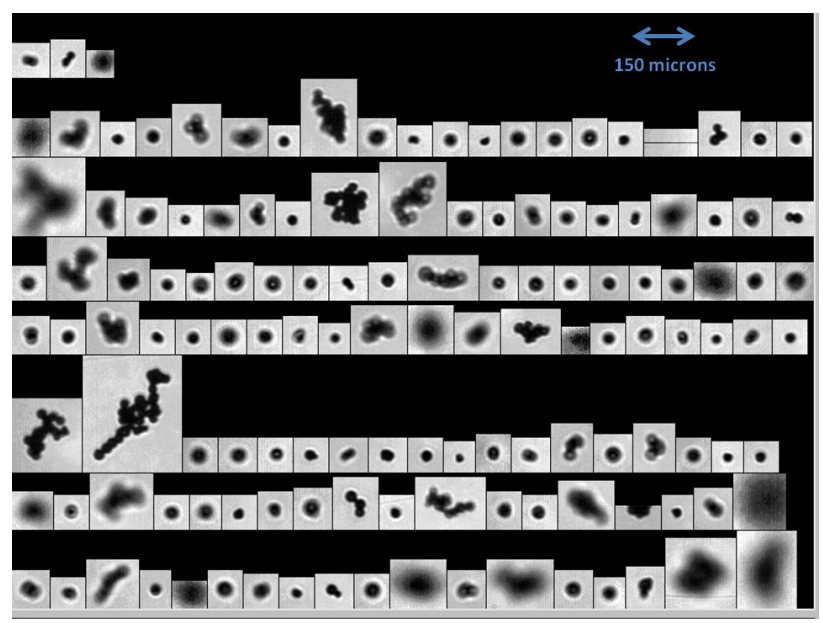

Fig. 6. CPI images of ice particles sampled between 22:20:00 and 22:20:02.

of FDA-forming regions. This region appears to have much higher proportions of frozen drops and FDAs compared to the Colorado anvils sampled by Lawson et al. (2003), although the other DC3 anvils (discussed below) are likely to be closer to those reported by Lawson et al. (2003) Images from regions with larger FDAs, such as those in Figs. 6 and 7 , suggest that single frozen drops, as well as doublets and triplets, are also present in these regions with larger FDAs.

Concentrations of ice particles from the CDP are unusually high (Fig. 4) but are within the upper ranges of number concentrations for cirrus clouds at these temperature reported by Krämer et al. (2009, Fig. 9) and well within the range reported by Heymsfield et al. (2009). Gayet et al. (2012) reported $>50 \mathrm{~cm}^{-3}$ of small (greater than $3 \mu \mathrm{m}$ ) ice particles in the overshooting tops near where they found frozen-drop chain aggregates, which are somewhat greater concentrations

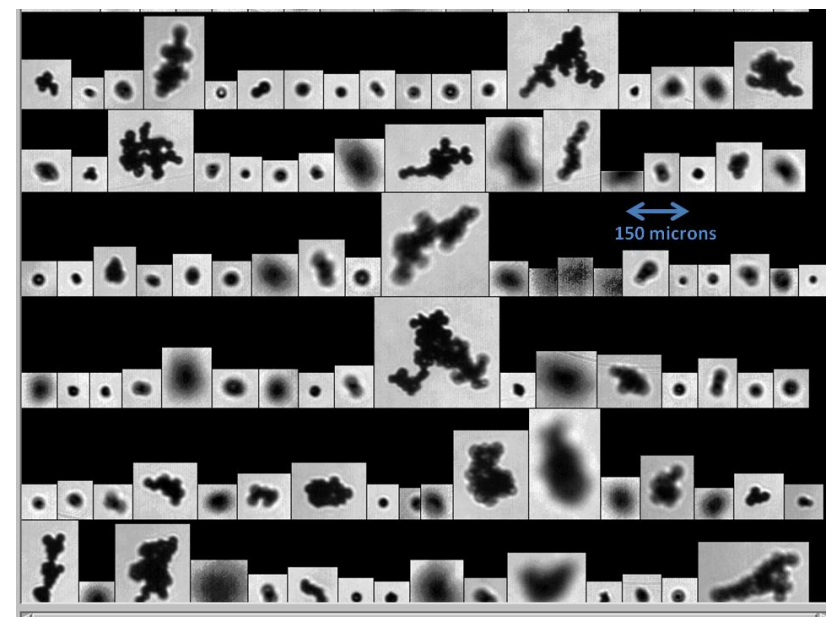

Fig. 7. CPI images of particles sampled between 22:25:51 and 22:25:53.

than found in the 6 June anvils. The CDP observations are consistent with the presence of high concentrations of frozen droplets in these cloud regions, as suggested by the CPI imagery. It is noteworthy that the high CDP concentrations are not uniformly distributed across the cloud (Fig. 4). The CDP concentrations do not follow the peaks in the 2DC concentrations, as might be expected if the CDP data were influenced significantly by shattering of larger ice particles. During the passes at 10.8 to $11.1 \mathrm{~km}$ altitude, near the lower part of the anvil, CDP concentrations (not shown) dropped below $1 \mathrm{~cm}^{-3}$.

OAP imagery from the 2DC and the 2DS signal from the 3V-CPI are given in Fig. 8, taken at times (22:25:54 and 22:45:24) corresponding to the CPI images of large aggregates (Fig. 7 shows CPI images corresponding to 22:25:5153). It is clear from examining the OAP image data that it is difficult to ascertain the individual frozen droplets in the FDAs with either of the OAPs. Imagery from the 2DS for this case appears to exhibit fewer large particles than from the $2 \mathrm{DC}$, a result that is confirmed by particle sizing algorithms. Many of the FDA particles should be quite fragile, and, indeed, examples of particle breakup are found in the 2DC images (Fig. 8). It seems likely that the $3 \mathrm{~V}-\mathrm{CPI}$ environment, where sampling is done within a tube, may be more conducive to particle breakup for these fragile particles than the sampling done with the 2DC instrument, although both will be influenced by shattering to some degree. Further testing and comparisons between these two instruments are planned to understand these differences in different types of cloud conditions and to determine the effectiveness of the inter-arrival time corrections for particle shattering. Because the CPI also samples within the $3 \mathrm{~V}$-CPI tube, these images may also be affected to some extent by breakup of fragile FDAs. Since the 2DC appears to handle the larger particles 

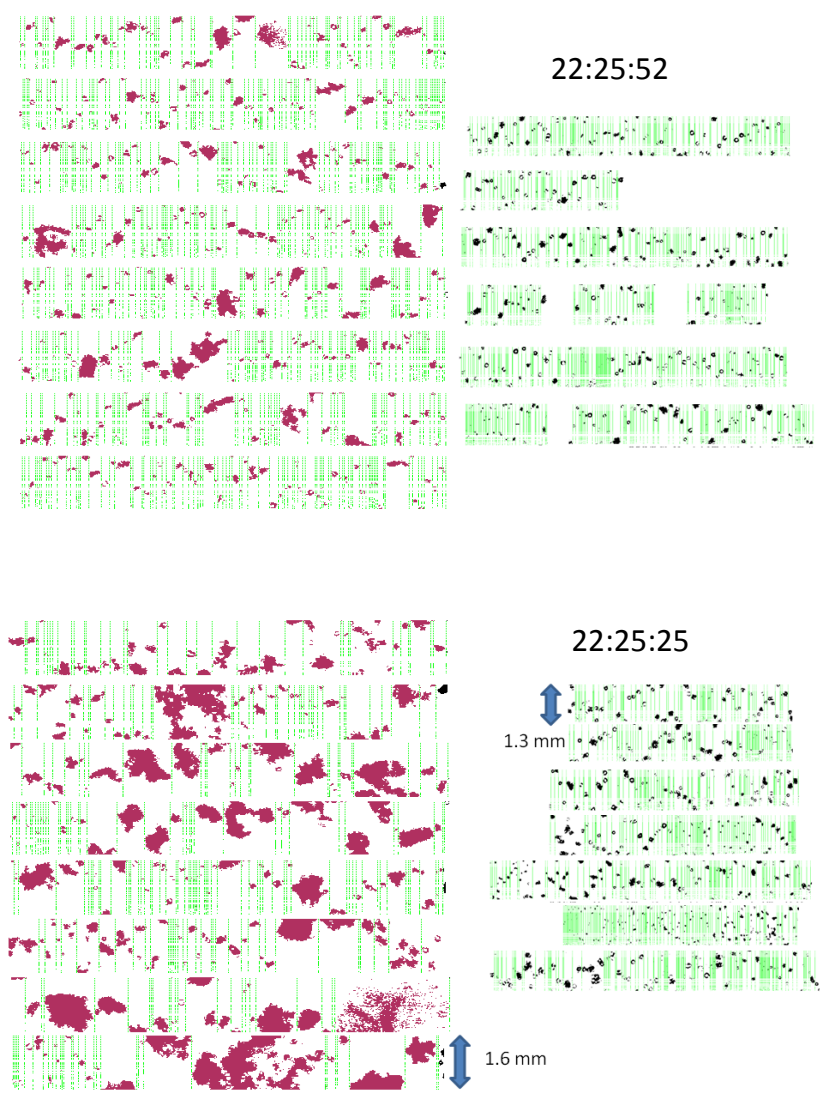

Fig. 8. 2DC (red) and 2DS (black) images taken near 22:25:52 (top) in the upper anvil and at 22:45:25 (bottom) in the lower anvil regions. Corresponding CPI images are shown in Fig. 7 for 22:25:52.

better in these clouds, as suggested by Fig. 8, we use it for our large particle data in the analysis presented below.

\subsection{Ice water content in the anvils: the role of small and large particles}

Ice water content (IWC) is computed from the CDP and the 2DC in order to determine the relative contribution of frozen droplets versus larger FDAs to the anvil ice. The primary intent of this analysis is to show the contribution to total IWC measured by the CLH-2 instrument by small and large particles. We estimate the IWC from the CDP by assuming the particles are spherical ice particles of density $0.91 \mathrm{~g} \mathrm{~cm}^{-3}$ and correct for the slight change in particle bin sizes caused by the difference in index of refraction of ice versus liquid water. Since the majority of particle types in the size range of the CDP were single frozen droplets, this method should be appropriate for these types of particles, but will likely overestimate the IWC from doublets, triplets or the few larger particles that are sampled by the CDP. The situation is not so straightforward for the case of the large particles measured by $2 \mathrm{DC}$, since we do not have an appropriate massdiameter relationship to use for these particles. The simplest approach is to assume a constant particle density with particle size and compute an effective density for all the particles sampled by the 2DC in a given time interval (here $1 \mathrm{~s}$ ). This is probably most applicable when the IWC from 2DC particles is dominated by particles of a given type and size, such as the period 22:25:45 to 22:26:45 (Fig. 9), where the particle volume distribution is dominated by large (mm-sized) particles. We use this time period to compute the volume concentration assuming a spherical ice particle, with the diameter of the sphere determined by the circle fit procedure described above. We then compute the effective density by taking the ratio of the IWC measured independently from the CLH-2 instrument (after subtracting the IWC computed from the CDP) with the particle volume concentration. The results are given in Fig. 10, which suggests an average density of $0.029 \mathrm{~g} \mathrm{~cm}^{-3}$ for the effective density of ice inside the inscribed circle used to compute the diameter of the particle from the 2DC imagery. This is a very small density, compared to typical ice particle densities in cirrus (e.g., Cotton et al., 2013, and references therein) and suggests a very low density of frozen droplets inside the inscribed circle, such as might be expected from the very long and thin chain-type particles shown in the CPI imagery. Under these conditions, the contribution of fragile chain-like particles may be underrepresented in the CLH-2 condensed water calculation due to premature fragmentation upstream of a narrow critical zone near the probe tip, where the transition to subisokinetic flow determines the particle enhancement factor. Thus, the average density reported here may be a lower limit for the actual density of the large FDAs. However since the purpose of the present analysis is to show the contribution by small and large particles to the total IWC as measured by the CLH2 instrument, the effective density calculated above serves this purpose. Further studies of the relationship between FDA particle size and IWC are planned to shed light on the potential undersampling of long-chain aggregates by the CLH-2, as suggested by these new observations.

The results of this analysis are presented in Fig. 11. Neither the IWC from the CDP nor the 2DC alone account for the total IWC measured by the CLH-2, but the sum of the two agrees well with the CLH-2 measurements. Thus, both the small frozen droplets and the FDAs are important contributors to the water content in this upper anvil region. It is also instructive to note in Fig. 11 that the small droplet contribution is greatest in the top of the southern anvil and on the edges of both anvils, whereby in the core of the anvils the main IWC contribution is due to large FDAs. Thus, the aggregation is heaviest in the central parts of the anvils and less aggregation has occurred on the anvil top and edges. The situation is depicted in idealized form in Fig. 12. 


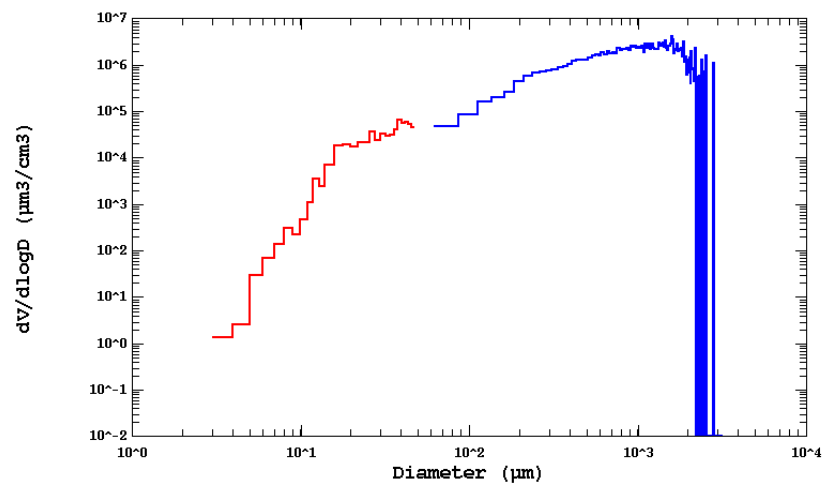

$=\begin{aligned} & 2 \mathrm{DC} \\ & \mathrm{CDP}\end{aligned}$

Fig. 9. Particle volume distribution for the period $22: 25: 45$ to 22:26:45 from the CDP (red) and 2DC instruments (blue). (Waterbased channel boundaries for the CDP are plotted here).

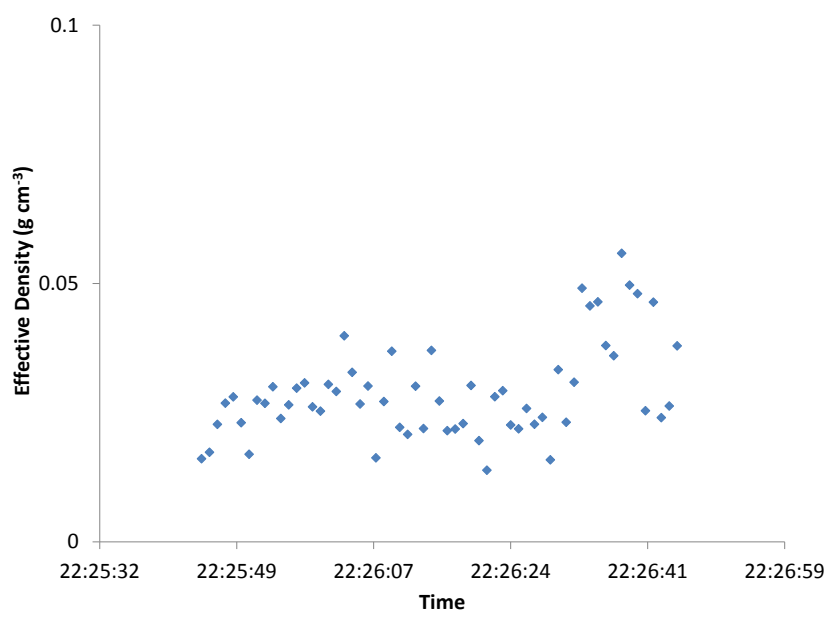

Fig. 10. Effective density of the ice inside the inscribed circle used to compute a size from the $2 \mathrm{DC}$ imagery. The average density is $0.029 \mathrm{~g} \mathrm{~cm}^{-3}$.

\subsection{Updraft structure of the storm as revealed by Doppler radar}

Just before and during the sampling period, the main cells of the storms were drifting slowly to the northeast (which is evident by comparing Figs. 1 and 3), although their anvils were developing and expanding downwind of the main cells. If we assume that the ice particles sampled in the anvil between 22:12 and 22:30 were formed near the main cell and then moved approximately with the ambient wind, then they would have originated in the main cell at approximately 21:25 for the first encounter with the southern storm anvil and 21:40 for the encounter with the northern storm anvil. Dual Doppler analysis using the CHILL and Pawnee radars for the southern storm at 21:25 is presented in Fig. 13. At this stage the storm was very much in a developing stage,
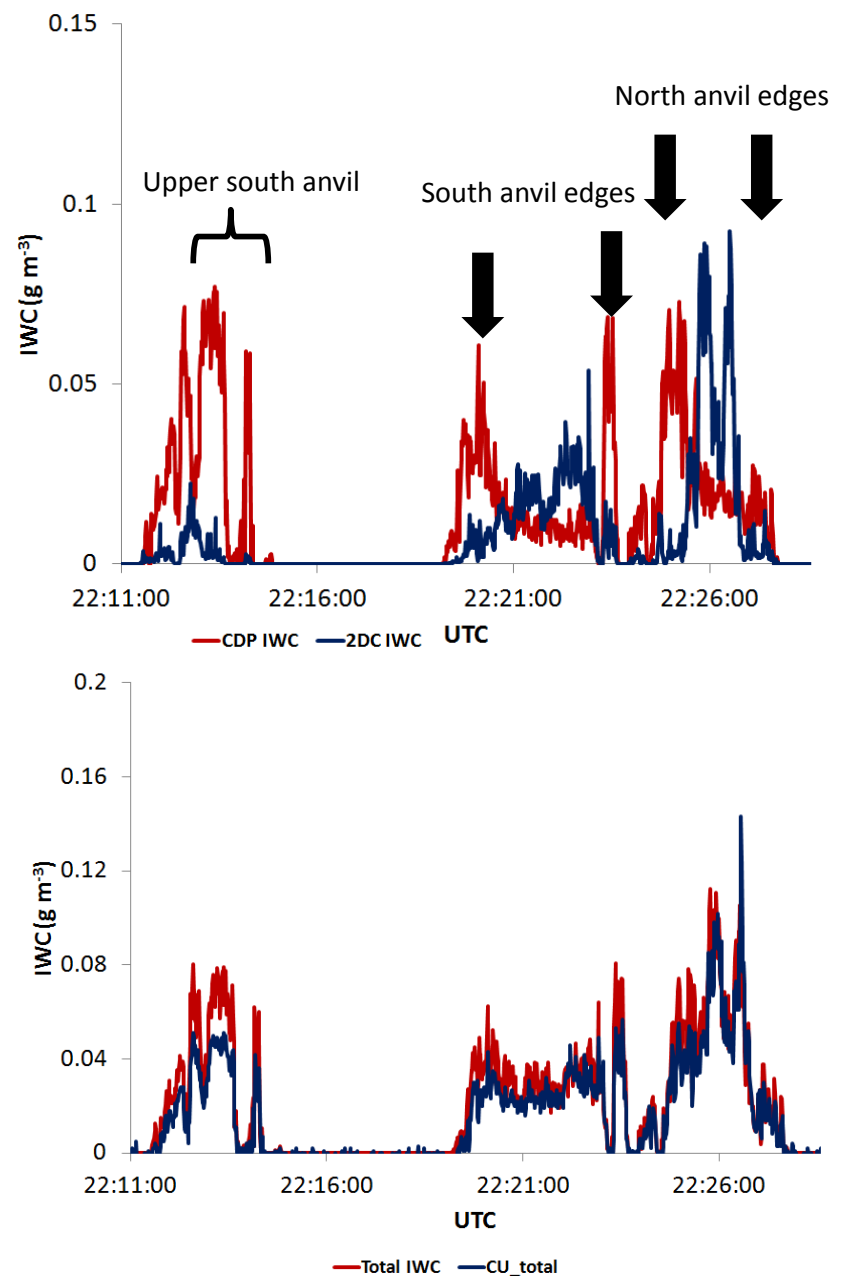

Fig. 11. Ice water content data from the anvil sampling depicted in Figs. 3 and 4. Ice water content from the CDP (red) and 2DC (blue) is depicted in the top plots. Combined CDP $+2 \mathrm{DC}$ ice water content (red) is compared with the ice water content measured by the CLH-2 (blue) in bottom plots.

without a major downdraft region and with only the beginnings of the anvil evident on radar (and confirmed by visual observations of the storm). Strong (above $45 \mathrm{dBZ}$ ) reflectivity areas were evident in the storm upper regions between 6 and $10 \mathrm{~km}$ altitudes, with lower reflectivities reaching up to $12 \mathrm{~km}$. Two areas of updraft are evident in the upper storm regions. The main updraft region had nearly vertical winds at its core over $15 \mathrm{~m} \mathrm{~s}^{-1}$ and extended from approximately 6 to $12 \mathrm{~km}$ altitude. The upper portion of the main updraft region between 10 and $12 \mathrm{~km}$ occurred in lower reflectivity cloud, suggesting that there were fewer and/or smaller hydrometeors in the top part of the updraft region than the lower half, although the updraft was still quite strong near the top of the cloud. Given the depth and strength of the main updraft, it could have easily carried droplets from warmer regions to altitudes cold enough for homogenous freezing. If enough 


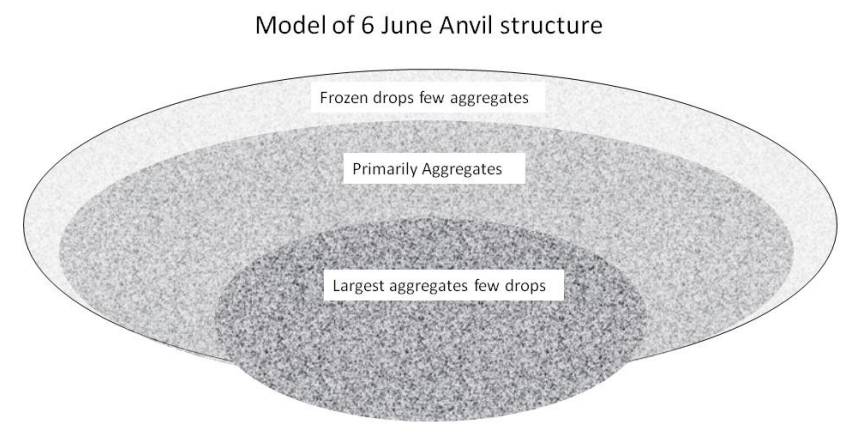

Fig. 12. Depiction of the microphysical structure of the 6 June anvils, based upon the types of ice particles encountered during sampling. The depiction is a vertical cross section perpendicular to the long axis of the anvil. Tops and sides of the anvils were dominated by frozen droplets, while the center and lower parts of the anvils had more aggregates and fewer frozen droplets.

droplets are present to freeze at this point, it is possible that there would be an intensification of the updraft due to the additional latent heat of freezing. Just to the east of the main updraft (red arrow in Fig. 13), a slight intensification of the updraft is observed in accord with this expectation. A second, slightly smaller and weaker updraft region is also evident to the east of the main cell (Fig. 13). It seems less likely that this updraft area would transport droplets from low levels compared to the main updraft, due to its more limited vertical extent; however, it might be a source of secondary activation of droplets if conditions were favorable (e.g., see Korolev and Mazin, 2003) or it might be a means by which pristine crystals from below are transported to higher levels where they could aggregate with FDAs produced higher up.

\section{FDAs in other anvils during DC3}

To assess the prevalence of FDAs, we conducted a survey of the other DC3 anvil sampling, looking for FDAs in conditions similar to those found in the 6 June storm and noting the variety of FDA morphologies that were encountered. A summary of some of the different morphological features of FDAs found in these anvils is provided in Fig. 14.

Since the G-V was used extensively for upper anvil sampling with the CPI during DC3, several anvil flights are available. The most common flight pattern included cross-anvil traverses, similar to those done on 6 June (Research Flight number 10, RF10). Many of these cases are expected to be studied in depth in future work, utilizing more data than have been examined here, so this survey represents a list of candidates for further study. We examined a large portion of the available CPI data from DC3, but it is possible that some of the FDA regions were missed. Furthermore the G-V was used mostly to sample the upper anvil regions in a manner similar to what was done on RF 10, so not all regions of the anvils were studied. Thus this survey is not intended to be extensive,
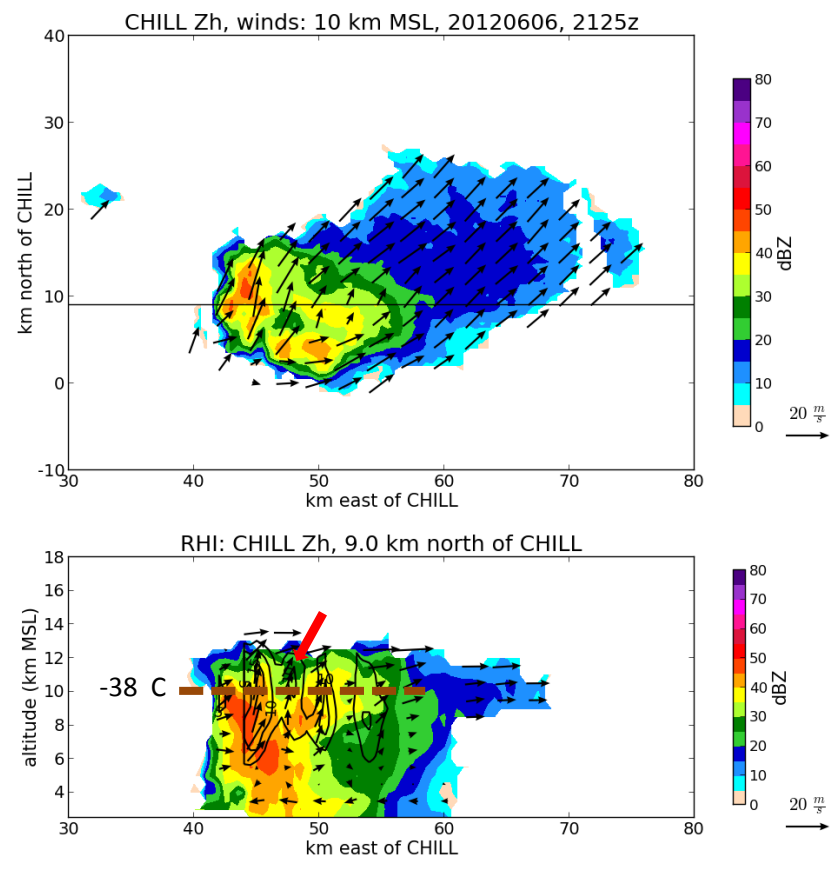

Fig. 13. Dual Doppler analysis of the wind and reflectivity field for the southern storm at 21:25 UTC. Contour lines of updraft strength at 5,10 and $15 \mathrm{~m} \mathrm{~s}^{-1}$ are included. The approximate location of the ambient $-38^{\circ} \mathrm{C}$ level is shown by the dashed line. The red arrow depicts an area of increasing updraft at temperatures colder than $-38^{\circ} \mathrm{C}$.

but rather to point out cases where FDAs were found. Except for one case (RF 17 on 22-23 June), nearly all the anvil measurements were made at temperatures colder than $-38^{\circ} \mathrm{C}$ required for homogenous freezing (Table 1). The sampling times and temperatures provided in Table 1 are intended to identify clouds that contained FDAs, but FDAs were not necessarily found throughout the cloud as discussed below.

The results of this survey are presented in Table 1. Nearly all of the anvil cases examined had some evidence for FDAs, but, as might be expected, there was considerable variation in the frequencies of their occurrence and the morphology of the FDAs. Several types of FDA-containing regions were encountered. These included regions where FDAs appeared to be the only particle types present, with only few exceptions (RF 2 and RF 10); regions where FDAs were found in the same anvils with other particle types; and regions containing FDAs that appeared to have aggregated with other crystal types. Considering the two main ice particle categories to be frozen droplets and depositional-grown ice crystals, we find them mixed in different ways. In one mixture the two categories are physically separated, but found in the same cloud in different proportions. The situation is analogous to what is referred to as an external mixture in aerosol science (where the external qualifier refers to aerosol chemical composition, while here we are using it to refer to ice particle types). In this case RF 2 and RF 10 are extreme examples, where the 


\begin{tabular}{|l|l|l|}
\hline & Simple forms \\
\hline & Heavily branched \\
\hline
\end{tabular}

Fig. 14. Examples of different forms of FDAs. Arrows point to examples of faceted crystals found in the matrix of frozen drops. See text for further explanation.

Table 1. Regions where FDAs were found during the DC3 campaign.

\begin{tabular}{|c|c|c|c|c|c|c|c|}
\hline ID & Date & $\begin{array}{r}\text { Temp. } \\
\left({ }^{\circ} \mathrm{C}\right)\end{array}$ & Times & $\begin{array}{r}\text { Altitude } \\
(\mathrm{km})\end{array}$ & $\begin{array}{l}\text { Midpoint } \\
\text { longitude }\end{array}$ & $\begin{array}{r}\text { Midpoint } \\
\text { latitude }\end{array}$ & Comment \\
\hline rf01 & 18 May & -58 & $22: 57-22: 30$ & 13 & $100.5^{\circ} \mathrm{W}$ & $41.3^{\circ} \mathrm{N}$ & $\begin{array}{l}\text { Regions of FDAs both internally and } \\
\text { externally mixed with other particle } \\
\text { types }\end{array}$ \\
\hline rf02 & 19-20 May & -51 to -56 & $23: 24-00: 28$ & 11 to 12 & $97.5^{\circ} \mathrm{W}$ & $36^{\circ} \mathrm{N}$ & $\begin{array}{l}\text { FDAs found alone, similar to RF10 (6 } \\
\text { June) case study }\end{array}$ \\
\hline rf04 & 25-26 May & -48 to -54 & $00: 38-01: 38$ & 11.5 to 12.1 & $99.5^{\circ} \mathrm{W}$ & $36^{\circ} \mathrm{N}$ & $\begin{array}{l}\text { Regions of FDAs both internally and } \\
\text { externally mixed with other particle } \\
\text { types }\end{array}$ \\
\hline rf 10 & 6 June & -47 to -60 & $22: 10-22: 55$ & 10.8 to 12.3 & $103.3^{\circ} \mathrm{W}$ & $41.0^{\circ} \mathrm{N}$ & FDAs found alone \\
\hline rf13 & 15 June & -45 to -60 & $20: 08-23: 48$ & 10.5 to 12.6 & $103.5^{\circ} \mathrm{W}$ & $40.6^{\circ} \mathrm{N}$ & $\begin{array}{l}\text { Primarily FDAs, with occasional } \\
\text { regions of other types }\end{array}$ \\
\hline rf14 & 16-17 June & -48 to -54 & $00: 00-00: 30$ & 11.6 to 12.21 & $97.4^{\circ} \mathrm{W}$ & $35.3^{\circ} \mathrm{N}$ & $\begin{array}{l}\text { Regions of FDAs both internally and } \\
\text { externally mixed with other particle } \\
\text { types }\end{array}$ \\
\hline rf17 & 22-23 June & -13 to -54 & $21: 30-02: 00$ & 6.8 to 12 & $101.5^{\circ} \mathrm{W}$ & $40.5^{\circ} \mathrm{N}$ & $\begin{array}{l}\text { Regions of FDAs both internally and } \\
\text { externally mixed with other particle } \\
\text { types }\end{array}$ \\
\hline rf 20 & 27-28 June & -39 to -57 & $22: 28-01: 22$ & 10.7 to 12.3 & $102.1^{\circ} \mathrm{W}$ & $40.4^{\circ} \mathrm{N}$ & $\begin{array}{l}\text { Only occasional FDAs in this anvil, } \\
\text { evidence for additional growth by } \\
\text { deposition }\end{array}$ \\
\hline rf 21 & 28-29 June & -37 to -52 & $23: 12-01: 06$ & 10.4 to 12.4 & $101.7^{\circ} \mathrm{W}$ & $40.0^{\circ} \mathrm{N}$ & $\begin{array}{l}\text { Regions of FDAs both internally and } \\
\text { externally mixed with other particle } \\
\text { types }\end{array}$ \\
\hline
\end{tabular}


mixture favored mostly FDAs, while RF20 is an example that favored depositional crystals with only a few FDA regions within the cloud. In the other type of mixture, FDAs appeared to be mixed with different crystal habits in the same ice particle, a situation analogous to an internal mixture in aerosol science. While it is difficult to infer the ice particle history solely from examining the particle imagery, there are many examples where a large, intact ice crystal is attached to a FDA (Fig. 14, internally mixed type 1), suggesting a collision between a FDA and a single large ice crystal was part of the aggregation process. Most of these cases involve a single plate-like crystal, which would have formed at a much warmer temperature than the temperature where it was observed (Bailey and Hallett, 2009). This observation has implications for our understanding of how FDAs are formed, as discussed below. A second type of internally mixed particle is suggested by the imagery. In these cases individual frozen drops are observed adjacent to multiple crystalline forms of similar sizes (Fig. 14, internally mixed type 2), which appear to be small columnar crystals that, unlike the type 1 cases, may have formed closer to the sampling location. These might have resulted from incorporation of locally grown ice crystals into the aggregate at temperatures closer to the observation temperature, or, perhaps, some of the faceted edges might be due to growth on the frozen droplets. Occasional chain aggregates of crystals without frozen drops were observed, but not nearly as frequently as FDAs in these storms. Most storms exhibited some combination of internal and external mixtures involving FDAs (Table 1).

In one rather small storm that was sampled during RF 17, FDAs were observed at temperatures warmer than the homogeneous freezing temperature (Table 1). (The later samples were from a much larger storm). A climb in this cloud region between 21:40 and 21:57 revealed a mix of graupel and FDAs (Fig. 15) in cloud that also contained supercooled liquid water (as determined from a Rosemount icing probe). FDA images were similar to those observed in colder anvils, especially for simple forms; however, long linear chains (Fig. 14) were qualitatively not observed to the same extent (i.e., in number and length) as in the colder anvil regions that were studied. Thus, it appears reasonable that some of the FDAs observed in the anvils may simply be the lowest-density type of graupel formed through riming which, owing to their low fall speeds, are easily transported to the anvil. It also seems likely that some of the FDA images are due to shattered fragments imaged by the CPI. For example, the edges of the large graupel particle in the lower left of Fig. 15 might easily break off during sampling. However, we note that the ice crystals in the internally mixed type 1 examples (Fig. 14) do not exhibit typical riming patterns on the crystal surface or edges, suggesting that they are not riming in the traditional manner, but rather colliding with existing assemblages of frozen droplets. Electrical forces are likely to be required in addition to the gravitational and aerodynamic

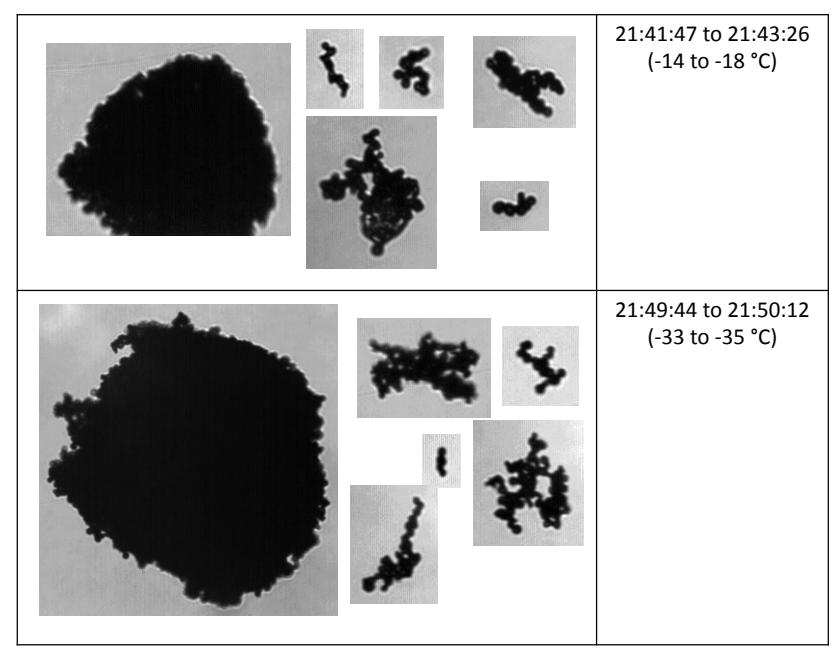

Fig. 15. Examples of FDAs found in warmer regions on 22 June 2012 together with examples of graupel found in the same regions. The graupel image in the lower left is approximately $1.1 \mathrm{~mm}$ in diameter and has been reduced in size by a third, relative to the other images, to fit in the figure.

accretion process to produce the longer-chain form of FDAs observed in many of the anvils.

\section{Discussion}

The results presented here suggest that chain FDAs as well as other low-density FDAs are common in strong US Midwestern continental thunderstorms such as those studied in DC3. Comparison of Figs. 5, 6, 7 and 14 with results from tropical/maritime storms, such as Fig. 10 in Gallagher et al. (2012) or earlier observations of maritime/tropical chain aggregates (e.g., Stith et al., 2004, Fig. 13), suggest a very similar chain-aggregate structure exists in the Midwestern clouds we studied, with the exception that many of the Midwestern chain aggregates were composed of frozen droplets instead of faceted ice crystals. However, unlike the Gallagher et al. (2012) results, where the relative contribution of small ice crystals to IWC was small (their Fig. 4), in the 6 June case the IWC from the frozen droplets was much greater near the upper and side regions of the anvil and necessary to explain the IWC that was measured independently of the ice particle sizing instrumentation. Our results suggest the possibility of a greater role for small ice particles (here frozen drops) in the upper regions of Midwestern anvils than in maritime/tropical anvil cirrus, for example the anvils described by Jensen et al. (2009).

For the 6 June case, frozen drops dominated the IWC on the tops and edges of the anvil, while larger FDAs dominated the IWC in the center and lower portions of the anvil (Figs. 11 and 12). If the drops were frozen first near the main cell of the storm, which seems most likely, then they survived for about 
$30 \mathrm{~min}$ in the anvil without enough depositional growth of ice to be detected in the particle imagery. This suggests that this anvil region did not have sufficient supersaturation with respect to ice to cause significant depositional growth of the ice phase. This is in agreement with the discussion in Gayet et al. (2012). However, our occasional encounters in other anvils with FDA particles exhibiting some faceted growth (Fig. 14; internally mixed, type 2 ice particles) suggest that some FDA regions may contain enough vapor to support depositional growth. Both of these ideas are supported by the observations of relative humidity (Fig. 4, bottom). Through much of the anvil pass, the relative humidity was very close to ice saturation, yet small pockets of slightly higher and lower supersaturation are found. Thus the conceptual model of the anvil in this case is one that primarily exhibits conditions of ice saturation, with small areas of super- and subsaturation present.

The results presented here offer some insights into how FDAs and chain FDAs might be formed. There is ample evidence (e.g., Rosenfeld and Woodley, 2000; Heymsfield et al., 2009; Lawson et al., 2010) that homogeneous freezing in strong convective systems is an important source of frozen droplets to the upper regions of these storms. Gayet et al. (2012) suggested that the supercooled droplets lifted in vigorous updrafts and frozen by homogenous nucleation produce a high concentration of frozen drops that then aggregate in intense electric fields to produce the chain aggregates of frozen droplets. This might explain our results, except that we also found FDAs consisting of frozen-drop chains attached to pristine plate crystals (Fig. 14), which form at warmer temperatures. Either the plate crystals were transported to colder regions intact where they then aggregated with FDAs, or the FDA aggregation process for these particles occurred at somewhat warmer temperatures. The limited anvil sampling done here at temperatures warmer than homogeneous freezing produced some observations of FDAs (Table 1, Fig. 15), which suggests that some FDAs are formed at warmer temperatures. Strong electric fields are certainly present at temperatures warmer than homogeneous freezing in these storms, so it might be expected that some fraction of the electrical FDA aggregation process occurs at warmer temperatures than suggested by Gayet et al. (2012). Perhaps a more general expression of the electrical hypothesis for the formation of these FDAs is that they form at any temperature where sufficient numbers of frozen droplets and strong electric fields coexist. Regions where droplets have been frozen homogeneously may be ideal locations due to high numbers of frozen droplets, but the formation regions are not likely to be exclusive to these locations. More work is needed to understand the relative importance of droplet riming versus electrical forces in promoting the formation of FDAs.

The distinction between the types of ice crystals found in continental anvils versus maritime/tropical anvils needs to be better documented, and their formation process needs to better understood, as the lifetimes of the ice particles, their ra- diative properties and their chemical composition are likely to be quite different. For example, FDAs contain all the cloud condensation nuclei present in each frozen droplet, suggesting a much different source of scavenged nuclei to the upper troposphere than would occur with depositionally grown ice crystals and aggregates of these crystals. Further studies are planned with the DC3 data set to address these important issues.

Acknowledgements. NCAR is supported by the National Science Foundation. Thanks are due to the many NCAR Earth Observing Laboratory staff members who contributed to the collection of the data presented here and to helpful comments by J. Haggerty, J. Jensen, J. Vivekanandan, V. Shcerbakov, and an anonymous reviewer. The assistance of J. DiGangi, A. O'Brien, and M. Zondlo of Princeton University, for their assistance with the data processing and quality assurance of the VCSEL data, is acknowledged. The Deep Convective Clouds \& Chemistry experiment (DC3) is sponsored by the US National Science Foundation (NSF), the National Aeronautics and Space Administration (NASA), the National Oceanic and Atmospheric Administration (NOAA), and the Deutsches Zentrum fur Luft- und Raumfahrt (DLR). The University of Colorado work is supported by the National Science Foundation under award number 1104642. The Colorado State University authors were supported by the NSF grant AGS-1010657 from the Physical and Dynamical Meteorology Program.

Edited by: M. Petters

\section{References}

Bailey, M. P. and Hallett, J.: A Comprehensive Habit Diagram for Atmospheric Ice Crystals: Confirmation from the Laboratory, AIRS II, and Other Field Studies, J. Atmos. Sci., 66, 2888-2899, doi:10.1175/2009JAS2883.1, 2009.

Barth, M., Cantrell, C., Brune, W., and Rutledge, S.: Scientific Program Overview (SPO) for a Deep Convective Clouds and Chemistry (DC3) Field Campaign, available at: http://www2.acd.ucar. edu/sites/default/files/dc3/DC3_SciencePlan-w.pdf (last access: 18 February 2014), 2012.

Connolly, P. J., Saunders, C. P. R., Gallagher, M. W., Bower, K. N., Flynn, M. J., Choularton, T. W., Whiteway, J., and Lawson, R. P.: Aircraft observations of the influence of electric fields on the aggregation of ice crystals, Q. J. Roy. Meteor. Soc., 131, 16951712, doi:10.1256/qj.03.217, 2005.

Cotton, R. J., Field, P. R., Ulanowski, Z., Kaye, P. H., Hirst, E., Greenaway, R. S., Crawford, I., Crosier, J., and Dorsey, J.: The effective density of small ice particles obtained from in situ aircraft observations of mid-latitude cirrus, Q. J. Roy. Meteor. Soc., 139, 1923-1934, doi:10.1002/qj.2058, 2013.

Davis, S. M., Hallar, A. G., Avallone, L. M., and Engblom, W.: Measurements of ice water content with a tunable diode laser hygrometer: Calibration procedure and inlet analysis, J. Atmos. Ocean. Tech., 24, 463-475, doi:10.1175/JTECH1975.1, 2007a.

Davis, S. M., Avallone, L. M, Weinstock, E. M, Twohy, C. H., Smith, J. B., and Kok, G. L.: Comparisons of in situ 
measurements of cirrus cloud ice water content, J. Geophys. Res., 112, D10212, doi:10.1029/2006JD008214, $2007 \mathrm{~b}$.

Dorsi, S. W., Kalnajs, L. E., Toohey, D. W., and Avallone, L. M.: A fiber-coupled laser hygrometer for airborne total water measurement, Atmos. Meas. Tech. Discuss., 6, 7355-7378, doi:10.5194/amtd-6-7355-2013, 2013.

Field, P. R., Heymsfield, A. J., and Bansemer, A.: Shattering and Particle Interarrival Times Measured by Optical Array Probes in Ice Clouds, J. Atmos. Ocean. Tech., 23, 1357-1371, 2006.

Gallagher, M. W., Connolly, P. J., Crawford, I., Heymsfield, A., Bower, K. N., Choularton, T. W., Allen, G., Flynn, M. J., Vaughan, G., and Hacker, J.: Observations and modelling of microphysical variability, aggregation and sedimentation in tropical anvil cirrus outflow regions, Atmos. Chem. Phys., 12, 66096628, doi:10.5194/acp-12-6609-2012, 2012.

Gardiner, B. A and Hallett, J.: Degradation of in-cloud forward scattering spectrometer probe measurements in the presence of ice particles, J. Atmos. Ocean. Tech., 2, 171-180, 1985.

Gayet, J.-F., Mioche, G., Bugliaro, L., Protat, A., Minikin, A., Wirth, M., Dörnbrack, A., Shcherbakov, V., Mayer, B., Garnier, A., and Gourbeyre, C.: On the observation of unusual high concentration of small chain-like aggregate ice crystals and large ice water contents near the top of a deep convective cloud during the CIRCLE-2 experiment, Atmos. Chem. Phys., 12, 727-744, doi:10.5194/acp-12-727-2012, 2012.

Heymsfield, A. J., Bansemer, A., Heymsfield, G., and Fierro, A. O.: Microphysics of Maritime Tropical Convective Updrafts at Temperatures from $-20^{\circ}$ to $-60^{\circ}$, J. Atmos. Sci., 66, 3530-3562, doi:10.1175/2009JAS3107.1, 2009.

Jensen, E. J., Lawson, P., Baker, B., Pilson, B., Mo, Q., Heymsfield, A. J., Bansemer, A., Bui, T. P., McGill, M., Hlavka, D., Heymsfield, G., Platnick, S., Arnold, G. T., and Tanelli, S.: On the importance of small ice crystals in tropical anvil cirrus, Atmos. Chem. Phys., 9, 5519-5537, doi:10.5194/acp-9-5519-2009, 2009.

Korolev, A. V and Mazin, I. P.: Supersaturation of water vapor in clouds, J. Atmos. Sci., 60, 2957-2974, 2003.

Korolev, A. V., Emery, E. F., Strapp, J. W., Cober, S. G., Isaac, G. A., Wasey, M., and Marcotte, D.: Small Ice Particles in Tropospheric Clouds: Fact or Artifact? Airborne Icing Instrumentation Evaluation Experiment, B. Am. Meteorol. Soc., 92, 967-973, doi:10.1175/2010BAMS3141.1, 2011.
Korolev, A. V., Emery, E. F., Strapp, J. W., Cober, S. G., and Isaac, G. A.: Quantification of the Effects of Shattering on Airborne Ice Particle Measurements, J. Atmos. Ocean. Tech., 30, 2527-2553, doi:10.1175/JTECH-D-13-00115.1, 2013.

Krämer, M., Schiller, C., Afchine, A., Bauer, R., Gensch, I., Mangold, A., Schlicht, S., Spelten, N., Sitnikov, N., Borrmann, S., de Reus, M., and Spichtinger, P.: Ice supersaturations and cirrus cloud crystal numbers, Atmos. Chem. Phys., 9, 3505-3522, doi:10.5194/acp-9-3505-2009, 2009.

Lawson, R. P.: Effects of ice particles shattering on the 2D-S probe, Atmos. Meas. Tech., 4, 1361-1381, doi:10.5194/amt-4-13612011, 2011.

Lawson, R. P., Baker, B. A., and Pilson, B. L.: In-Situ measurements of microphysical properties of mid-latitude and anvil cirrus, Proceedings, 30th International Symposium on Remote Sensing of Environment, Honolulu, Hawaii, November, 707-710, 2003.

Lawson, R. P., Jensen, E., Mitchell, D. L., Baker, B., Mo, Q., and Pilson, B.: Microphysical and radiative properties of tropical clouds investigated in TC4 and NAMMA, J. Geophys. Res., 115, D00J08, doi:10.1029/2009JD013017, 2010.

Rosenfeld, D. and Woodley, W.: Deep convective clouds with sustained superooled liquid water down to $-37.5^{\circ} \mathrm{C}$, Nature, 405 , 440-442, doi:10.1038/35013030, 2000.

Stith, J. L., Dye, J. E., Bansemer, A., Heymsfield, A. J., Grainger, C. A., Petersen, W. A., and Cifelli, R.: Microphysical Observations of Tropical Clouds, J. Appl. Meteorol., 41, 97-117, doi:10.1175/1520-0450(2002)041<0097:MOOTC>2.0.CO;2, 2002.

Stith, J. L., Haggerty, J. A., Heymsfield, A., and Grainger, C. A.: Microphysical Characteristics of Tropical Updrafts in Clean Conditions, J. Appl. Meteorol., 43, 779-794, doi:10.1175/2104.1, 2004.

Zondlo, M. A., Paige, M. E., Massick, S. M., and Silver, J. A.: Development, flight performance, and calibrations of the NSF Gulfstream-V vertical cavity surface emitting laser (VCSEL) hygrometer, J. Geophys. Res.-Atmos., 115, D20309, doi:10.1029/2010JD014445, 2010. 